University of Nebraska - Lincoln

DigitalCommons@University of Nebraska - Lincoln

\title{
Identifying Fecal Sources in a Selected Catchment Reach Using Multiple Source-Tracking Tools
}

\author{
Jason R. Vogel \\ USGS, jason.vogel@ou.edu \\ Donald M. Stoeckel \\ USGS \\ Regina Lamendella \\ Univ. of Cincinnati, Cincinnati, $\mathrm{OH}$ \\ Ronald B. Zelt \\ USGS \\ Jorge W. Santo Domingo \\ USEPAOffice of Research and Development, National Risk Management Research Lab. \\ See next page for additional authors
}

Follow this and additional works at: https://digitalcommons.unl.edu/usgsstaffpub

Part of the Earth Sciences Commons

Vogel, Jason R.; Stoeckel, Donald M.; Lamendella, Regina; Zelt, Ronald B.; Domingo, Jorge W. Santo; Walker, Steven R.; and Oerther, Daniel B., "Identifying Fecal Sources in a Selected Catchment Reach Using Multiple Source-Tracking Tools" (2007). USGS Staff -- Published Research. 19.

https://digitalcommons.unl.edu/usgsstaffpub/19

This Article is brought to you for free and open access by the US Geological Survey at DigitalCommons@University of Nebraska - Lincoln. It has been accepted for inclusion in USGS Staff -- Published Research by an authorized administrator of DigitalCommons@University of Nebraska - Lincoln. 


\section{Authors}

Jason R. Vogel, Donald M. Stoeckel, Regina Lamendella, Ronald B. Zelt, Jorge W. Santo Domingo, Steven R. Walker, and Daniel B. Oerther 


\title{
Identifying Fecal Sources in a Selected Catchment Reach Using Multiple Source-Tracking Tools
}

\author{
Jason R. Vogel,* Donald M. Stoeckel, Regina Lamendella, Ronald B. Zelt, Jorge W. Santo Domingo, \\ Steven R. Walker, and Daniel B. Oerther
}

\begin{abstract}
Given known limitations of current microbial source-tracking (MST) tools, emphasis on small, simple study areas may enhance interpretations of fecal contamination sources in streams. In this study, three MST tools-Escherichia coli repetitive element polymerase chain reaction (rep-PCR), coliphage typing, and Bacteroidales 16S rDNA host-associated markers - were evaluated in a selected reach of Plum Creek in south-central Nebraska. Water-quality samples were collected from six sites. One reach was selected for MST evaluation based on observed patterns of $E$. coli contamination. Despite high $\boldsymbol{E}$. coli concentrations, coliphages were detected only once among water samples, precluding their use as a MST tool in this setting. RepPCR classification of $E$. coli isolates from both water and sediment samples supported the hypothesis that cattle and wildlife were dominant sources of fecal contamination, with minor contributions by horses and humans. Conversely, neither ruminant nor human sources were detected by Bacteroidales markers in most water samples. In bed sediment, ruminant- and human-associated Bacteroidales markers were detected throughout the interval from 0 to $0.3 \mathrm{~m}$, with detections independent of $E$. coli concentrations in the sediment. Although results by $\boldsymbol{E}$. coli-based and Bacteroidales-based MST methods led to similar interpretations, detection of Bacteroidales markers in sediment more commonly than in water indicates that different tools to track fecal contamination (in this case, tools based on Bacteroidales DNA and $E$. coli isolates) may have varying relevance to the more specific goal of tracking the sources of $E$. coli in watersheds. This is the first report of simultaneous, toolbox approach application of a librarybased and marker-based MST analyses to flowing surface water.
\end{abstract}

$\mathrm{E}$ XCESSIVE levels of fecal bacteria are the most common cause of beneficial-use impairment in $\mathrm{Ne}$ braska streams and account for impairment of 66 of the 111 stream segments $(59 \%)$ on the 2004 State's Section 303(d) list (Nebraska Department of Environmental Quality, 2004). To achieve the Clean Water Act goal of "swimmable" waters, fecal indicator bacteria levels in streams must be reduced to comply with water quality standards. Fecal contamination may originate from point or nonpoint sources. Generally, point sources of fecal contamination include discrete sources such as wastewater treatment outfalls, storm sewers and com-

J.R. Vogel and R.B. Zelt, USGS, 5231 S. 19th St., Lincoln, NE 68512. D.M. Stoeckel, USGS, 6480 Doubletree Ave., Columbus, OH 43229. R. Lamendella and D.B. Oerther, Dep. of Environmental Engineering, Univ. of Cincinnati, Cincinnati, OH 45220. J.W. Santo Domingo, USEPA Office of Research and Development, National Risk Management Research Lab., 26 Martin Luther King Dr., MS-387, Cincinnati, OH 45268. S.R. Walker, Nebraska Dep. of Environmental Quality, 1200 "N" St., Suite 400, P.O. Box 98922, Lincoln, NE 68509. Received 27 June 2006. *Corresponding author (jrvogel@usgs.gov).

Published in J. Environ. Qual. 36:718-729 (2007).

Technical Reports: Surface Water Quality

doi:10.2134/jeq2006.0246 bined sewers, and discharges from large animal-feeding operations. Nonpoint sources are diffuse and include: (i) agricultural sources, including livestock access to streams and riparian zones, land application of livestock waste, and irrigation from livestock waste lagoons or pits; (ii) domestic or municipal sources, including pet waste, septic systems, and land application of municipal biosolids; and (iii) wildlife sources, including deer, geese, ducks, raccoons, and other nondomesticated animals (Wilhelm and Maluk, 1998).

Control techniques (i.e., treatment to achieve permitted effluent concentrations, implementation of bestmanagement practices [BMPs]) need to be implemented for both point and nonpoint sources if impaired water bodies are to meet water quality objectives (e.g., achieving total maximum daily load [TMDL] objectives). Monitoring of fecal indicator bacteria distribution in the environment is a valuable tool for helping resource managers identify BMPs that will most effectively reduce fecal contamination. Best management practices specifically targeted to reduce the effect of livestock (e.g., cattle) on stream water quality include exclusion fencing/riparian buffers, finding an alternative water source for the livestock, finding an alternative shade source for the livestock, and management of pasture stocking density (Agouridis et al., 2005). Implementation plans for BMPs in impaired water bodies now often include identification of fecal contamination sources by microbial source-tracking (MST) methods (Simpson et al., 2002; Zhang et al., 2002; Moyer and Hyer, 2003; Hyer and Moyer, 2004). The MST methods often are divided into two general categoriesthose that require development of a culture collection reference-isolate library (library-dependent, such as Escherichia coli [E. coli] and enterococci) and those that use established host-associated markers (libraryindependent, such as coliphage and Bacteroidales). For E. coli-based, library-dependent methods, methodscomparison studies have concluded that dependability tends to be inconsistent, and the recommendation is for extensive validation of MST results (Griffith et al., 2003; Stoeckel et al., 2004; Moore et al., 2005). Libraryindependent methods have demonstrated relatively high accuracy but can be prone to false negative results (Griffith et al., 2003).

The objective of this study was to apply several MST analyses in a toolbox approach to determine whether

Abbreviations: MST, microbial source tracking; PCR, polymerase chain reaction; Rep-PCR, repetitive element PCR; BMP, best management practice; TMDL, total maximum daily load; CFU, colony forming unit; DO, dissolved oxygen; OWML, Ohio Water Science Center Microbiology Lab.; OTU, operational taxonomic unit. 
human, livestock, or other animal wastes were sources of fecal bacteria to Plum Creek, Nebraska. Three tools were applied in this study: an E. coli repetitive element polymerase chain reaction (rep-PCR) method, a coliphage-typing method, and a Bacteroidales $16 \mathrm{~S}$ rDNA host-associated marker method. This article describes the application of these three MST tools to a small catchment reach within the Plum Creek watershed and comparison of the data obtained by use of each tool. A justification for extrapolating the MST results to the entire watershed is presented, and the article discusses potential positive and negative implications of BMP implementation within the Plum Creek watershed based on these MST results.

\section{MATERIALS AND METHODS Site Selection}

Plum Creek drains $580 \mathrm{~km}^{2}$ of rural land in south-central Nebraska (Fig. 1) and is a perennial tributary to the Platte River. Plum Creek flows in a southeasterly direction for most of its length until it turns north and flows to its confluence with the Platte River. The climate of the Plum Creek watershed is classified as semiarid continental with cold winters and a latespring to early-summer hydroperiod (Wahl, 1981). Soil parent material is predominantly unconsolidated deposits of loess (Wahl, 1981). Grassland is the most extensive land cover in the Plum Creek watershed (part of U.S. hydrologic unit 10200101), with irrigated row crops, hay, and small grains composing the secondary land uses. High-intensity, short-duration thunderstorms common to this region produce most peak stream flows; stream flows in Plum Creek near Smithfield $(15 \mathrm{~km}$ upstream from the confluence) exceed $0.57 \mathrm{~m}^{3} \mathrm{~s}^{-1}$ less than $10 \%$ of the time. Plum Creek drains into the middle Platte River (segment MP2-20000), which is listed on the 2004 Nebraska Section 303(d) list of impaired water bodies for $E$. coli, fecal coliform bacteria, and temperature. A TMDL for fecal coliform bacteria for segment MP2-20000 was approved by USEPA on 16 May 2003 (Nebraska Department of Environmental Quality, 2004).

Results from the State's preliminary monitoring studies in summer 2001 show that Plum Creek was the most contaminated of the perennial tributaries to the middle reaches of the Platte River, with a geometric mean concentration of 1100 CFU/100 mL for fecal coliforms ( $n=18$ samples). Although the primary contact recreational use is not assigned to Plum Creek, this level of fecal contamination is much higher than State water quality standards for primary contact recreation (400 CFU/100 mL; exceeded in 13 of 18 samples) (P.A. O'Brien, personal communication, 2003). The Plum Creek watershed was chosen for study because it represents an important source of fecal contamination to the middle Platte River segment.

Digital map data were used to characterize the drainages of Plum Creek, as well as canals, natural tributaries, and major lakes within the Plum Creek watershed. Land use characteristics and animal feeding operation density were summarized by tributary watersheds and main-stem catchment reaches.

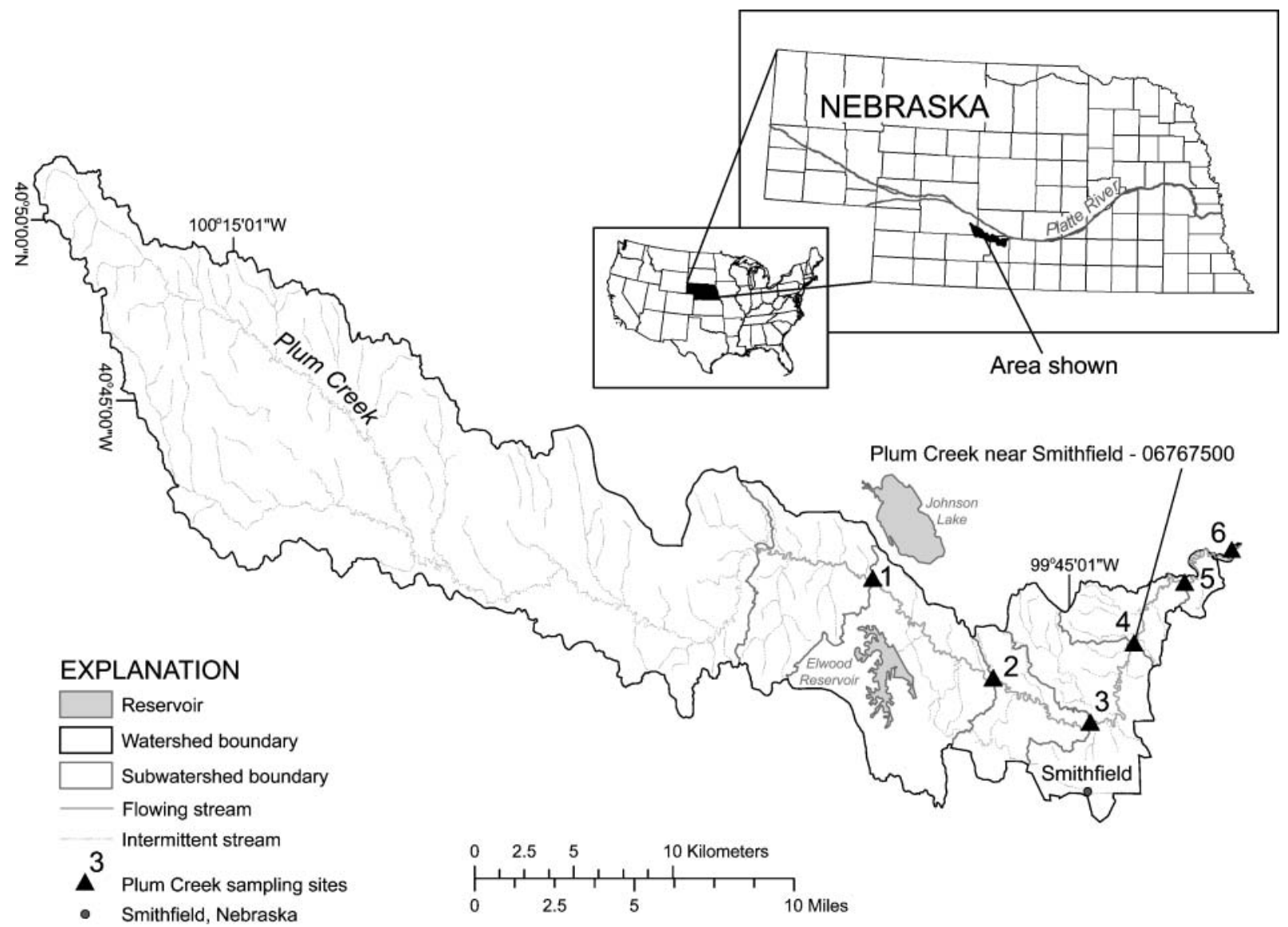

Fig. 1. Location of Plum Creek watershed in south-central Nebraska, including six sampling sites and contributing reach catchments on the main stem of Plum Creek. 
During spring 2004, onsite reconnaissance was made at 86 locations identified by digital map analysis (at locations where roads crossed a water body). Where surface water was present (22 locations), a grab sample was collected and analyzed for temperature, $\mathrm{pH}$, specific conductance, turbidity, concentrations of dissolved oxygen (DO), nitrate-nitrogen, and E. coli. Of the 22 sites with water, 16 were on the main stem of Plum Creek, four were on irrigation canals that pass through the watershed, and two were at reservoirs (Johnson Lake and Elwood Reservoir). Flow was not detected in any natural tributary to Plum Creek during base flow conditions.

On the basis of the results of the reconnaissance sampling, six sampling sites were selected for this study, including the stream-gaging station near Smithfield (Fig. 1, Site 4), and five other sites on the perennially flowing segment of Plum Creek (Fig. 1). The most upstream site at which excessive levels of fecal contamination were detected (Site 2; E. coli concentrations greater than $298 \mathrm{CFU} / 100 \mathrm{~mL}$ ) was chosen for MST evaluation. This strategy allowed a small area from which to collect fecal source samples to represent the E. coli population from various sources (the stream reach between Sites 1 and 2). The upper boundary of the area upstream from Site 1 in Fig. 1 represents the extent of the perennially flowing segment of Plum Creek. The area upstream from the perennially flowing segment was not considered for sampling because it only flowed for very short durations during intense storms.

Land use characteristics and catchment areas of each of the six inter-site reaches and the entire watershed are summarized in Table 1. In general, each of the reaches supported similar land uses, consisting mostly of grassland and row-crop acreage. The reach catchments upstream from Sites 1 and 5 have a smaller percentage of row crops than the other four reaches. The catchment upstream from Site 2 has a larger percentage of water because Elwood Reservoir is located within that catchment; however, stored water is delivered only to irrigation canals and did not discharge to Plum Creek (except through springs). An informal survey of cattle in the six catchment reaches, completed in the summer of 2005, was used to estimate cattle populations along each reach. The reach ending at Site 2 had the greatest density of cattle, followed by the reach ending at Site 4; the area upstream from Site 1 had the lowest density of cattle at the time of the survey. Because the perennially flowing segment of Plum Creek is similar along its entire length in terms of land use, agricultural practices, topography, climate, and water quality, the MST results from the reach upstream from Site 2 (that was analyzed using MST tools) may be useful for targeting BMPs for the entire watershed.

\section{Sample Collection}

Water was analyzed in situ for $\mathrm{pH}$, temperature, specific conductance, turbidity, and DO using USGS standard methods for collecting field measurements (USGS, 2004). Flowweighted water samples representing the stream cross-section were collected every other week from May through December 2004 (Edwards and Glysson, 1999; USGS, 2004). Three aliquots were distributed for separate analyses. One was shipped overnight at $4{ }^{\circ} \mathrm{C}$ to the USGS Ohio Water Science Center Microbiology Laboratory (OWML) for analysis of coliphage concentration (4 May through 21 Sept. 2004 only) and filtration in preparation of Bacteroidales host-associated marker extraction (only data from Site 2 are presented in this paper). The second aliquot was hand delivered for analysis of $E$. coli concentration (Ward Labs, Kearney, NE) within the 6-h hold time (USEPA, 2000). The third aliquot was shipped for suspended sediment analysis by the methods of Guy (1969) at the USGS Iowa Water Science Center Sediment Laboratory (Iowa City, IA).

Bed sediment samples were collected every other week from 9 Aug. 2004 to 1 Dec. 2004 at one site (Site 2) at three depths (0-0.1 m [top], 0.1-0.2 m [middle], and 0.2-0.3 m [bottom]) using a US BMH-53 hand-held piston-type bed material sampler (Edwards and Glysson, 1999). Triplicate cores were collected at the one-quarter, one-half, and threequarters points across the stream, sliced into depth increments, and shipped overnight at $4^{\circ} \mathrm{C}$ to OWML. At OWML, the samples were homogenized and analyzed for $E$. coli concentrations and filtered in preparation of Bacteroidales hostassociated marker extraction. Coliphage concentrations were not determined for the bed sediment samples.

Fecal samples were collected from cattle, horses, human septic tanks, and wildlife (most likely raccoons and opossums) in July and August 2004 in the reach between Sites 1 and 2 and shipped overnight at $4^{\circ} \mathrm{C}$ to OWML for cultivation of $E$. coli isolates and filtration of Bacteroidales host-associated markers. Coliphage isolates were not collected from fecal samples. Cattle and horse fecal samples were collected fresh from the animals in pastures within the basin. Fecal samples were collected from 100 of approximately 1500 cattle, and 6 of 8 horses resident within the reach between Sites 1 and 2. Human septic tank samples were collected by inserting a sterilized swab into the cleanout port of area septic tanks. Within the targeted reach, 10 of 15 houses representing approximately 50 of 75 permanent residents were sampled. Wildlife fecal samples (62 fecal samples collected; most likely raccoons or opossums) all were collected in the riparian area directly adjacent to Plum Creek. Samples were collected only if they were moist and appeared fresh. The percentage of the population that these samples represent is unknown.

\section{Microbial Cultivation and Enumeration}

Male-specific $(\mathrm{F}+)$ coliphages in water were analyzed using the single agar layer (SAL) procedure (USEPA Method 1602;

Table 1. Land use in each of the reach catchments, the perennial watershed of Plum Creek (sum of six reach catchments), and the entire watershed. (modified from National Agricultural Statistics Service, 2004)

\begin{tabular}{|c|c|c|c|c|c|c|c|}
\hline \multirow[b]{2}{*}{ Site name (see Fig. 1) } & \multirow{2}{*}{$\begin{array}{l}\text { Catchment area between site } \\
\text { and next upstream site }\end{array}$} & \multicolumn{6}{|c|}{ Land use between sites } \\
\hline & & Grassland & Row crops & Small grains and hay & Fallow cropland & Urban & Water \\
\hline & $\mathbf{k m}^{2}$ & & 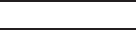 & $\%$ of area & & & \\
\hline Site 1 & 43 & 74 & 20 & 3 & 0.7 & 0.5 & 0.2 \\
\hline Site 2 & 65 & 49 & 37 & 4 & 1 & 2 & 7 \\
\hline Site 3 & 24 & 58 & 38 & 4 & 0.4 & 0.8 & 0.4 \\
\hline Site 4 & 46 & 50 & 46 & 4 & 0.4 & 0.7 & 0.1 \\
\hline Site 5 & 17 & 82 & 14 & 4 & 0.6 & 0.6 & 0.1 \\
\hline Site 6 & 4.6 & 50 & 39 & 9 & 0.6 & 0.9 & 0.3 \\
\hline All six reaches $\dagger$ & 200 & 59 & 33 & 4 & 0.8 & 1 & 2.3 \\
\hline Entire watershed & 565 & 68 & 24 & 5 & 1.5 & 0.5 & 0.8 \\
\hline
\end{tabular}

$\dagger$ Perennially flowing segment of watershed. 
USEPA, 2001). The analysis volume was $100 \mathrm{~mL}$. Data were reported as plaque-forming units (pfu) per $100 \mathrm{~mL}$.

Water samples were analyzed for $E$. coli concentration by cultivation on mTEC agar (USEPA, 2000). Following enumeration, presumptive E. coli colonies were picked to 96-well transfer plates containing fresh mTEC agar. Transfer plates were shipped overnight on ice to the OWML. Upon receipt, transfer plates were pre-incubated at $35^{\circ} \mathrm{C}$ for $2 \mathrm{~h}$ to allow resuscitation and grown out at $44.5^{\circ} \mathrm{C}$ overnight. Each culture was streaked for purity onto eosin methylene blue (EMB) agar and, if the culture exhibited characteristic green sheen, single colonies were picked and cultivated in Luria Bertani (LB) broth for further use. Glycerol stocks were prepared for each pure culture and held at $-70^{\circ} \mathrm{C}$ until further use.

Bed sediment samples were prepared for E. coli analysis at the OWML by the method described by Francy and Darner (1998). Twenty grams of sediment were placed into a bottle containing $200 \mathrm{~mL}$ of phosphate buffer. Each sample was mixed on a wrist-action shaker for $45 \mathrm{~min}$ and allowed to settle for $30 \mathrm{~s}$. The supernatant was analyzed for most probable numbers concentration of $E$. coli by use of Colilert reagents in Quantitray-2000 format (Idexx Corporation, Westbrook, ME). Isolation of $E$. coli colonies from wells was done by sterilizing the paper tray back, puncturing, and streaking culture from positive wells to modified mTEC agar. Isolated colonies were restreaked to EMB and, if they exhibited characteristic green sheen, glycerol stocks were prepared for further use.

Known source fecal samples were mixed to disperse solids and streaked for isolation on mTEC agar (USEPA, 2000). Streak plates were cultivated, isolates picked, and purified on EMB, then stored in the same manner as the water-cultivated E. coli isolates.

Total DNA extractions were performed for each pure culture using DNA extraction kits (MO BIO, Carlsbad, CA). The DNA concentration of each extract was measured, and DNA samples were diluted to a consistent concentration (50 ng $\mu \mathrm{L}^{-1}$ ) for use as the DNA fingerprinting template. Normalized DNA extracts were held at $-20^{\circ} \mathrm{C}$ for later use.

The rep-PCR was performed using BOX A1R primer (5'-CTA CGG CAA GGC GAC GCT GAC G-3') in a commercially available kit (Diversilab System, Bacterial Barcodes Inc., Athens, GA). AmpliTaq polymerase (Applied Biosystems, Foster City, CA) was added for all PCR using the following cycling conditions: $94^{\circ} \mathrm{C}$ for $2 \mathrm{~min}$; 35 cycles of $94^{\circ} \mathrm{C}$ for $30 \mathrm{~s}, 50^{\circ} \mathrm{C}$ for $30 \mathrm{~s}$, and $70^{\circ} \mathrm{C}$ for $90 \mathrm{~s}$; and $3 \mathrm{~min}$ at $70^{\circ} \mathrm{C}$. The PCR products were separated by use of a BioAnalyzer (Agilent, Palo Alto, CA). Image analysis utilized both the proprietary Diversilab analysis reporting system and BioNumerics software (Applied Maths, Sint-MartensLatem, Belgium).

"Fingerprint" analysis in the Diversilab System is done by means of a similarity-based dendogram created from unweighted, paired-group means with arithmetic averages (UPGMA) clustering of Pearson similarity coefficients. This dendogram was used to assign each isolate to an operational taxonomic unit (OTU) on the basis of similarity of patterns observed with a repeated-measures isolate. To further evaluate assignment of OTU, files representing each fingerprint were imported to the BioNumerics image analysis tool as described previously (Stoeckel et al., 2004). The BioNumerics software was used to create alternative dendograms and to classify isolates to source by use of a $\mathrm{k}=1$ nearest neighbor approach (custom script "Bootstrap" available from Applied Maths, Sint-Martens-Latem, Belgium). Further information about selection and validation of the isolate-classification approach is included in the supplemental material (available at http://jeq.scijournals.org).

\section{Bacteroidales Analysis}

Water samples (50-100 mL) collected from the Plum Creek watershed were filtered at OWML through $47-\mathrm{mm}, 0.2-\mu \mathrm{m}$ polycarbonate filters within $24 \mathrm{~h}$ of collection, transferred to 15-mL conical centrifuge tubes, and stored at $-80^{\circ} \mathrm{C}$ until analyzed. Fecal samples were held at $-80^{\circ} \mathrm{C}$ as slurries suspended in phosphate buffer. Sediment samples also were held at $-80^{\circ} \mathrm{C}$ pending analysis.

Fecal total DNA extractions were performed with the UltraClean Fecal DNA Isolation Kit at USEPA (Cincinnati, $\mathrm{OH}$ ) according to the manufacturer's instructions (MO BIO Laboratories, Inc. Carlsbad, CA). Approximately $250 \mu \mathrm{L}$ of fecal slurry from each known source sample were used for DNA extractions. For water samples, DNA was extracted directly from whole filters using the UltraClean Soil DNA Isolation Kit (MO BIO Laboratories). Sediment total DNA also was extracted using the Ultraclean Soil DNA Isolation Kit. Total DNA was eluted in $50 \mu \mathrm{L}$ of $10 \mathrm{~m} M$ Tris buffer and quantified using a NanoDrop ND-1000 UV spectrophotometer (NanoDrop Technologies, Wilmington, DE). Extracted total DNA was diluted using ultra pure water to achieve a final concentration of $1.5 \mathrm{ng} \mu \mathrm{L}^{-1}$. The PCR for fecal and sediment samples was performed with both undiluted template and with a 10 -fold dilution to reduce matrix interference. To test for possible cross contamination, control blanks for total DNA extractions were performed using $250 \mu \mathrm{L}$ of ultra pure water samples. Extracted total DNA was stored at $-20^{\circ} \mathrm{C}$ until further processing.

Bacteroidales 16S rDNA PCR assays were performed on reference feces samples, water samples, and sediment samples using four primer sets as originally described by Bernhard and Field (2000) under conditions detailed in Table 2 (general fecal marker Bac32 [G], ruminant-associated markers CF128 and CF193 [R1 and R2], and human-associated marker HF183 [H]). The final PCR solutions contained $2.5 \mathrm{~m} M$ dNTP mixture, $0.06 \%$ BSA, $0.25 \mu M$ primer, 0.625 units of Ex Taq DNA polymerase, and $1 \mu \mathrm{L}$ of diluted or undiluted template in Takara Ex Taq buffer. Reactions were done with a DNA Engine 2 Tetrad thermalcycler (MJ Research, South San Francisco, CA). Template concentrations for fecal samples were adjusted to

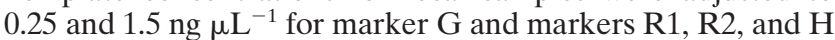
amplification, respectively. General PCR conditions were denaturing at $94^{\circ} \mathrm{C}$ for $2 \mathrm{~min}$, followed by 30 cycles (fecal samples) or 35 cycles (sediment and water samples) of denaturing $\left(94^{\circ} \mathrm{C}\right.$ for $1 \mathrm{~min}$ ), annealing (for $1 \mathrm{~min}$, see Table 2), extension $\left(72^{\circ} \mathrm{C}\right.$ for $\left.1 \mathrm{~min}\right)$, and a final extension step $\left(72^{\circ} \mathrm{C}\right.$ for $7 \mathrm{~min})$. The PCR products were separated using $1 \%$ agarose gel stained with GELSTAR (Cambrex, Baltimore, MD).

\section{Quality Assurance/Quality Control}

Two field equipment blanks and nine field duplicate samples were collected during the study and analyzed as inde-

Table 2. Bacteroidales primer sets and annealing temperatures (from Bernhard and Field, 2000).

\begin{tabular}{|c|c|c|c|}
\hline Target & $\begin{array}{c}\text { Forward } \\
\text { primer }\end{array}$ & $\begin{array}{c}\text { Reverse } \\
\text { primer }\end{array}$ & $\begin{array}{c}\text { Annealing } \\
\text { temperature }\end{array}$ \\
\hline & & & ${ }^{\circ} \mathbf{C}$ \\
\hline All Bacteroidales (marker G) & Bac32F & Bac708R & 53 \\
\hline $\begin{array}{l}\text { Ruminant-origin Bacteroidales } \\
\text { (marker R1) }\end{array}$ & CF128F & Bac708R & 62 \\
\hline $\begin{array}{l}\text { Ruminant-origin Bacteroidales } \\
\text { (marker R2) }\end{array}$ & CF193F & Bac708R & 62 \\
\hline $\begin{array}{l}\text { Human-origin Bacteroidales } \\
(\text { marker } \mathbf{H})\end{array}$ & HF183F & Bac708R & 63 \\
\hline
\end{tabular}


pendent samples. Positive and negative control reactions were included with every PCR reaction set for both E. coli and Bacteroidales. Cultivation steps included at least one blank analysis per 20 test samples to detect cross contamination, if present. For Bacteroidales DNA marker detection, all PCR preparations were completed in a laminar flow hood following the USEPA quality-assurance guide for using PCR methods on environmental samples (USEPA, 2004).

Detection limit assays were conducted for all four markers. Known amounts of feces were spiked into ultra pure water and serially diluted and amplified at 35 cycles for each primer set. In addition, background levels of fecal sample DNA extracts were spiked into ultra pure water to detect possible matrix inhibition.

\section{Statistical Analysis}

Arithmetic or geometric means were calculated on the basis of normality of the data as determined by a preponderance of results from four normality tests (Shapiro-Wilk W test [Shapiro and Wilk, 1965], Anderson-Darling test [Anderson and Darling, 1954], Martinez-Iglewicz test [Martinez and Iglewicz, 1981], and Kolmogorov-Smirnov test [Dallal, 1986]) on the data set for each property from each site. The arithmetic mean was used if normality was not rejected on the original data set, and geometric means calculated if normality was not rejected on the log-transformed data set. The Kruskal-Wallis One-Way ANOVA on Ranks test $(\alpha=0.05)$ was used to test for difference between medians (Ott, 1993).

\section{Supplemental Material}

The authors recognize that method validation studies on library-dependent methods for microbial source tracking suggest that these approaches are prone to error, particularly when they rely on small libraries (Griffith et al., 2003; Stoeckel et al., 2004; Moore et al., 2005). Although the library in this study is small relative to current recommendations (for example, USEPA, 2005), the potential fecal source populations in the study area were well represented in the library and the known source reference feces. Extensive quality control was incorporated into analysis of these results as a means of validating interpretations. Full presentation of the quality control evaluations detracts from this article as a whole and is not of interest to many readers; therefore, these evaluations are presented as a supplemental section.

\section{Stream Flow and Water Quality Properties}

Stream flow was measured at the time of sample collection from each sampling site (data available in Hitch et al., 2004, 2005; Nebraska Department of Natural Resources, 2005). Analysis of these stream flow values indicates that springs were active between Sites 1 and 2 during the entire period of sample collection and between Sites 5 and 6 during September and early October. The springs between Sites 5 and 6 likely are active during fall because of local furrow irrigation. Most of the area between Sites 5 and 6 also has different topography than the rest of the watershed (relatively flat Platte River Valley with shallow water tables vs. hills with deeper water tables) that would promote seepage of infiltrated irrigation water into the ground water during periods of intensive irrigation. The flow in the headwaters of Plum Creek upstream from Site 1 during base flow conditions also is assumed to be a result of springs. The average increase in flow rate due to springs between Sites 1 and 2, calculated from stream flow data measured during non-runoff sampling (all samples except 12 July, 23 August, 7 September, and 1 December), was $0.21 \mathrm{~m}^{3} \mathrm{~s}^{-1}$ (75\% increase).

Water temperature, specific conductance, turbidity, and DO were measured onsite during sample collection. Data for these water quality properties and $\mathrm{pH}$ were previously published in Hitch et al. (2004, 2005). Comparisons using a Kruskal-Wallis One-Way ANOVA on Ranks $(\alpha=0.05)$ on this data indicated that water temperatures were not significantly different among the six sampling sites on any sample date. However, median specific conductance was higher and turbidity and DO lower at Site 1 than at the other sampled sites. In addition, median specific conductance at Site 2 was higher and median turbidities at Sites 2 and 3 were lower than at downstream sites. The differences in water quality properties at these sites may be a result of ground water effects from springs in these reaches of the stream.

\section{RESULTS AND DISCUSSION \\ Suspended Sediment, $E$. coli, and Coliphage Concentrations}

\section{Quality Assurance/Quality Control}

Replicate analyses were completed to evaluate whether samples collected at the same time would result in similar measurements. Results for all five duplicate suspended sediment concentrations and for all nine duplicate log-transformed E. coli concentrations were within $10 \%$ for all replicates collected during the study. Coliphage concentrations in replicate samples were all less than the limit of detection.

\section{Water Samples}

Suspended sediment and E. coli concentrations were measured in 93 water samples collected from the six sampling sites (Table 3 ). Averaged over time, the maxi-

Table 3. Geometric mean, median, and interquartile range (IQR) for suspended sediment and $E$. coli concentrations, and coliphage detection rate from biweekly water-quality samples collected at six sampling sites on Plum Creek from May through December 2004.

\begin{tabular}{|c|c|c|c|c|c|c|c|}
\hline \multirow[b]{2}{*}{ Site name (see Fig. 1) } & \multicolumn{3}{|c|}{ Suspended sediment } & \multicolumn{3}{|c|}{ E. coli } & \multirow{2}{*}{$\frac{\text { Coliphage }}{\text { Detection rate (detections/number of samples) }}$} \\
\hline & Geometric mean & Median & IQR & Geometric mean & Median & IQR & \\
\hline & \multicolumn{3}{|c|}{$\mathrm{mg} \mathrm{L}^{-1}$} & \multicolumn{3}{|c|}{$-c f u / 100 \mathrm{~mL}$} & \\
\hline Site 1 & 29 & 26a & 41.5 & $55 \dagger$ & $65 e$ & 106 & $0 / 0$ \\
\hline Site 2 & 70 & $86 b$ & 43.3 & 270 & $270 f$ & 637 & $\mathbf{1 / 1 0}$ \\
\hline Site 3 & $\mathbf{8 5} \dagger$ & $124 b c$ & 103 & 381 & $406 f$ & 693 & $0 / 1$ \\
\hline Site 4 & 149 & 200bcd & 262 & 534 & $645 f$ & 1235 & $0 / 3$ \\
\hline Site 5 & $187+$ & 257d & 203 & $466+$ & $480 f$ & 950 & $0 / 0$ \\
\hline Site 6 & $131 \dagger$ & 212cd & 179 & 302 & $505 f$ & 1037 & $\mathbf{0 / 1 0}$ \\
\hline
\end{tabular}

$\dagger$ Used geometric mean for comparison purposes even though normality tests could not reject normality of this data set.

$\ddagger$ Values with the same letters are not significantly different using a Kruskal-Wallis One-Way ANOVA on Ranks (alpha less than 0.05). 
mum geometric mean suspended sediment concentration was for samples from Site 5; however, concentrations gradually increased from Site 1 to Site 4 . Between Sites 4 and 6 the median suspended sediment concentrations were not significantly different. Averaged over time, the maximum geometric mean $E$. coli concentration was for samples from Site 4; however, concentrations increased from Site 1 to Site 2, but were not significantly different from Site 2 down to Site 6 (Table 3). Figure 2A depicts temporal trends of $E$. coli concentrations at all six sampling sites. During the study coliphage concentrations were determined in 24 water samples collected from all sites and were detected only once, at Site 2 (Table 3).

\section{Sediment Samples}

The concentration of $E$. coli in sediment samples was highest in the upper $0.1 \mathrm{~m}$ of streambed sediment (Fig. 2B) and peaked on 19 October 2004 during a period of base flow conditions (no storms) in Plum Creek. Flow results from Sites 2 and 4 are included to demonstrate similarities and differences in the flow at the two
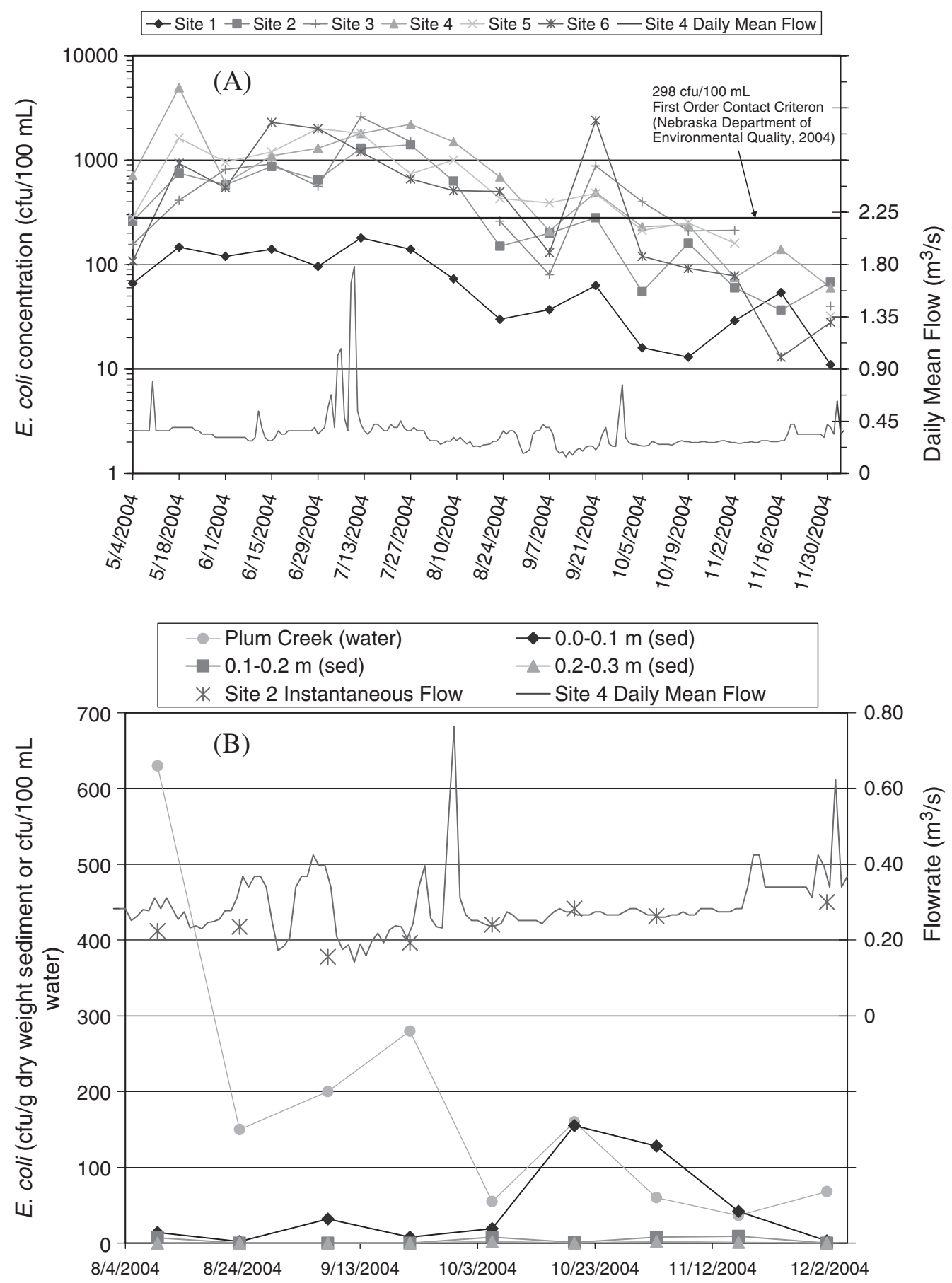

Fig. 2. E. coli concentration in (A) water samples at the six sampling sites along Plum Creek and in (B) water and bed sediment samples at Site 2. 
sites, and to indicate storms that occurred between sample collection dates.

\section{E. coli-Based Microbial Source Tracking Quality Assurance/Quality Control Summary}

Several approaches for classification of water-isolated E. coli as to source were evaluated for accuracy. Results of these evaluations, replicate analyses, and classification accuracy on single-blind spiked samples are presented in the supplemental materials.

\section{Known Source Library}

The known source library contained rep-PCR patterns for 201 cattle-isolated E. coli, 29 horse-isolated E. coli, 69 human-isolated E. coli, and 110 wildlifeisolated E. coli. Because of the small study area $\left(65 \mathrm{~km}^{2}\right.$ catchment reach between Sites 1 and 2), these isolates represented a substantial proportion of the contributing population for these fecal source groups (between about 7 and $75 \%$ of individuals sampled). In all, 220 OTUs were assigned among the 409 known source isolates-207 specific to single sources and 13 to multiple sources (called cosmopolitan isolates). Figure 3 depicts the sources of isolates composing the known source library and the distribution of OTU among the sources.

\section{E. coli Classification}

Classification results for $E$. coli isolated from water and sediment samples are shown in Fig. 4. In both cases, cattle and wildlife were indicated as the major sources of fecal contamination to the stream and sediment with possible contributions by horses and humans. Failure to detect horse feces in a known source spike sample (see supplemental material) means that horses may be an undetected contributor to these samples, although the scarcity of horses within the reach (eight animals) diminishes this possibility. Detection of multiple sources (and subsequent classification as an unknown source) in the wildlife spike sample means the relative contribution by wildlife may be underestimated by this test. Also, classification of a source outside of our library as cattle indicates that cattle may be overestimated by use of $E$. coli-based MST as applied in this study. The low-level detection rates of horse and human contribution fall into the range of false positive classifications (see supplemental section) in this study and, as such, are not considered credible evidence of fecal contamination from those sources.

Evaluation of the data from water samples by season (Table 4) did not show evidence of a seasonal component to the relative contribution by each source. May through June were considered spring, July through September were considered summer, and October through December were considered autumn for purposes of the seasonal evaluation. A chi-square test of independence also indicated that the frequency of detections from each source (cattle, horse, human, wildlife, unknown) in each season did not vary. However, because the number of detections for horses and humans were less than five, the chi-square test of independence may not be conclusive for testing whether or not these two sources vary by season.

\section{Bacteroidales-Based Microbial Source Tracking Quality Assurance/Quality Control}

Laboratory Blanks and Detection Limit Assays. All 14 water blanks collected during Bacteroidales filtration tested negative for all four markers. Assays were completed using DNA from fecal source material to determine the detection limit of the PCR-based assays. From these assays, the general feces marker G, the two ruminant feces markers R1 and R2, and the humanassociated marker $\mathrm{H}$ had average detection limits of $1.15 \times 10^{-14}, 1.15 \times 10^{-12}, 1.15 \times 10^{-11}$, and $1 \times 10^{-9} \mathrm{~g}$ DNA, respectively.

Distribution in Reference Materials. Known-source feces samples were used to test how the markers were distributed in feces collected from the study area. Marker G was detected in $90 \%$ or greater of cattle, horse, and human-derived samples, but in only $32 \%$ of the wildlife-
(A)

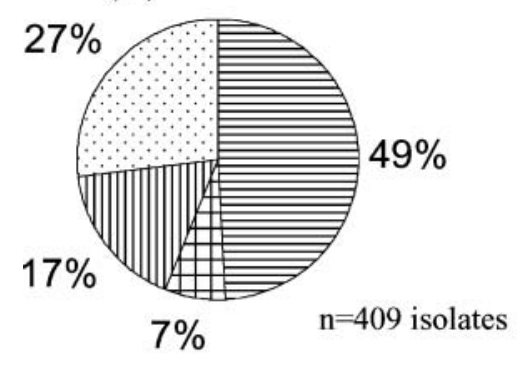

(B)

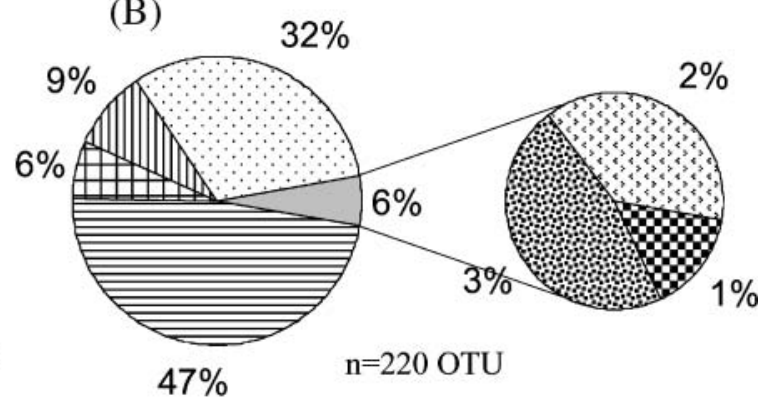

\begin{tabular}{|lll|}
\hline 目 Cattle & ⿴囗十 Horse & m Human \\
a Cattle-Horse & 国 Cattle-Wildlife & 国 Human-Wildlife \\
\hline
\end{tabular}

Fig. 3. Distribution of (A) isolates among sources and (B) operational taxonomic units (OTU) among sources in the known source library (inset pie chart in [B] depicts cosmopolitan OTUs). 
(A)

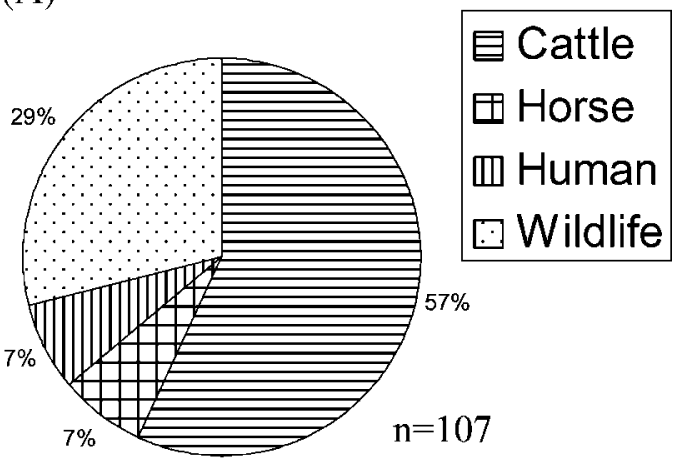

(B)

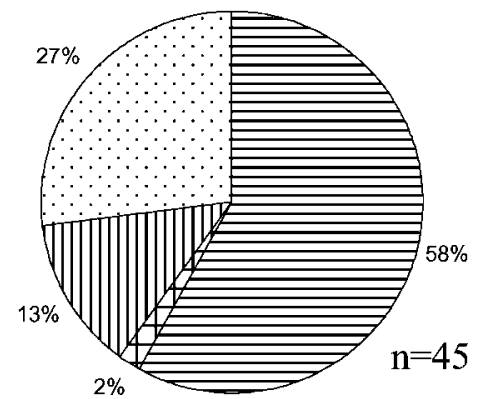

Fig. 4. Pie charts depicting classification of (A) water-isolated $E$. coli and (B) sediment-isolated $E$. coli. Only isolates that could be assigned to a single host of origin are included in the plots.

derived samples. This result could be because wildlife feces samples were collected from the banks of the stream and were not as fresh as other feces samples when analyzed, or it could be that bacteria carrying marker $\mathrm{G}$ often were not present in fecal communities from the wildlife sampled. Markers R1 and R2 were detected in more than $90 \%$ of cattle- and horse-derived samples, but only in 3\% or fewer of wildlife and human samples. Marker $\mathrm{H}$ was detected in $40 \%$ of human-derived fecal samples, but only 1,0 , and $0 \%$ of cattle, horse, and wildlife feces samples, respectively (Lamendella et al., 2007).

\section{Bacteroidales-Based Fecal-Source Classification}

DNA extracted from Site 2 environmental samples collected between 4 May 2004 and 19 Oct. 2004 (for water) and between 9 Aug. 2004 and 2 Nov. 2004, (for bed sediment) was tested for presence of the four markers to indicate fecal contamination sources. Although all extracts from water samples from Site 2 tested positive when challenged against marker $G$, only one, in July, showed evidence of ruminant (cattle or horse) fecal contamination (markers R1 or R2), and none showed evidence of human fecal contamination (marker $\mathrm{H})$. This could be because contamination was less than the method detection limit (as an indication of intensity of fecal contamination; E. coli concentrations generally were in the hundreds but peaked in July above 1000 CFU/100 mL; Fig. 2) or because fecal contamination at the site did not come from detectable sources (such as birds, dogs, or other animals in the area).

DNA extracted from bed sediment samples at Site 2 most frequently contained marker $\mathrm{G}$ in the surface slice (86\%, from Table 5); overall, $81 \%$ of bed sediment samples contained marker G. Markers R1 and R2 each

Table 4. Classification of $E$. coli isolates to source by season in water samples.

\begin{tabular}{lccc}
\hline Parameter & $\begin{array}{c}\text { Spring } \\
\text { (May-June) }\end{array}$ & $\begin{array}{c}\text { Summer } \\
\text { (July-Sept.) }\end{array}$ & $\begin{array}{c}\text { Autumn } \\
\text { (Oct.-Dec.) }\end{array}$ \\
\hline Cattle & $21(42 \%)$ & $21(44 \%)$ & $19(34 \%)$ \\
Horse & $2(4 \%)$ & $3(6 \%)$ & $3(5 \%)$ \\
Human & $4(8 \%)$ & $1(2 \%)$ & $2(4 \%)$ \\
Wildlife & $9(18 \%)$ & $10(21 \%)$ & $12(21 \%)$ \\
Unknown & $14(28 \%)$ & $13(27 \%)$ & $20(36 \%)$ \\
\hline
\end{tabular}

were detected in $14 \%$ of bed sediment samples, although seldom in the same sample. Marker R1 was detected once at each depth, whereas marker R2 was detected twice at the 0- to 0.1-m depth and once at the 0.2 - to $0.3-\mathrm{m}$ depth. Among the five samples amplified by ruminant markers, in only one (surface slice sample collected 24 Aug. 2004) were both ruminant markers detected. In two instances (R1 once at the middle depth and R2 once at the deep depth), ruminant markers were amplified when marker $\mathrm{G}$ was not. Finally, marker $\mathrm{H}$ was detected in DNA extracted from $19 \%$ of the bed sediment samples, with three of four detections on the same date (detected at all three depths) (Table 5). Marker $\mathrm{H}$ was detected in three samples when marker $\mathrm{G}$ was not detected (once at the each depth, all on the same date; one of these three samples coincided with the sample where marker R1 was detected but marker G was not).

\section{Interpretations of the Study Area and Reference Material Characteristics}

Samples for MST analysis, supported by local reference materials representing various fecal sources, were collected from a small catchment (between Sites 1 and 2 ) that was selected for intensive investigation. This smaller subcatchment was used to generalize the results for the rest of the perennially flowing portion of the Plum Creek watershed. This generalization is defensible because of similarities in land use (Table 1), agricultural practices, topography, climate, water quality properties, and E. coli concentrations (Table 3). However, more coliphage and Bacteroidales marker might be detected downstream from this site if detection limits for these tests require more fecal contamination than was present

Table 5. Detection of Bacteroidales-based markers, by depth, from bed sediment samples at Site $2(n=7$ at each depth).

\begin{tabular}{lrccc}
\hline & \multicolumn{4}{c}{ Marker } \\
\cline { 2 - 5 } Sample depth & \multicolumn{1}{c}{ G $\dagger$} & \multicolumn{1}{c}{ R1 } & \multicolumn{1}{c}{ R2 } & H \\
\hline $0-0.1$ m depth & $6(86 \%)$ & $1(14 \%)$ & $2(29 \%)$ & $1(14 \%)$ \\
$0.1-0.2$ m depth & $6(86 \%)$ & $1(14 \%)$ & $0(0 \%)$ & $2(29 \%)$ \\
$0.2-0.3$ m depth & $5(71 \%)$ & $1(14 \%)$ & $1(14 \%)$ & $1(14 \%)$ \\
Overall (0-0.3 m depth) & $17(81 \%)$ & $3(14 \%)$ & $3(14 \%)$ & $4(19 \%)$ \\
\hline
\end{tabular}

$\dagger G$, general fecal marker; $R 1$ and $R 2$, ruminant-associated markers; $H$, human-associated marker. 
at site 2. Cumulative contributions by additional populations in the downstream subcatchments might increase marker concentrations to above the detection limit.

Of the three intended MST analyses, coliphage typing had to be abandoned early in the study because of rare detection (1 of 24 samples [from Table 3] had measurable F-specific coliphage concentrations). Prior reports have indicated that F-specific coliphage are not commonly found in all host populations, even when they carry E. coli (Calci et al., 1998; Cole et al., 2003). In the setting of this investigation, rare detection of coliphage in stream water negated its usefulness for MST.

Tests of the assumptions behind MST results by use of $E$. coli libraries generally supported the approach in this setting, although the support is not strong enough to allow reliance exclusively on this approach (see USEPA [2005] for full details of assumptions and supplemental material for tests and results). On the basis of the results of these tests, the E. coli-based MST tool as applied in this setting provided reproducible assignment to types, the types tended to be unique to the host, and classifications of dominant fecal contamination sources, where attempted, are expected to provide useful evidence of contamination sources with the following exceptions: (i) the tool was unable to detect when a source was not represented in the library, so if the sanitary survey results of likely sources failed then the analysis may also fail; (ii) the tool made more false assignments for one source (wildlife; raccoons and opossums) that may have used feces of other hosts as a food source; (iii) the tool was unable to detect feces from the source that had few isolates in the library (horses; limited representation because there were very few horses in the watershed).

Reference materials also were tested for the presence of Bacteroidales-based host-associated markers. Marker $\mathrm{G}$, which was expected to be present in every feces sample, was present in most cattle-, horse-, and humanderived feces, but only some wildlife-derived feces. The age of wildlife feces compared with other reference feces or incomplete distribution of marker $G$ among wildlife are potential explanations for this result. Among the host-associated markers, R1 and R2 were detected in most cattle and horse reference materials but not in wildlife and human reference materials. Marker H, on the other hand, was detected only some of the time in human reference material. The incomplete distribution of this marker among human populations was previously reported (Bernhard and Field, 2000). Thus, interpretation of marker $\mathrm{H}$ detection was limited to indication of human fecal contamination in this study, but not to indicate absence of fecal contamination from human sources.

\section{Interpretations of Fecal Contamination Sources to Plum Creek Based on Microbial Source Tracking Results}

\section{E. coli-Based Tool}

The E. coli-based MST tool provided evidence that the dominant sources of fecal contamination at Site 2 were cattle and wildlife. Although the distribution of classifications is similar to the composition of the library (half cattle, a quarter wildlife), which might be taken to indicate random classification to source, the demonstrated ability to identify sources of some spiked samples gives credibility to this evidence of contamination sources. The pattern of error exposed in validation efforts indicated that cattle detections may have been overestimates of the true contribution of cattle-origin fecal contamination and that horses and wildlife detections may have been underestimates of the true contribution of fecal contamination with their respective origins. With the caveat of these potential misrepresentations, it appears, based on interpretation of the E. coli MST data, that both cattle and wildlife contributed substantial portions of fecal contamination to the stream and that horses and humans contributed relatively little or no fecal contamination to the stream at site 2 .

Potential for sediment to act as a reservoir of E. coli, which could later contaminate the water column, is relevant to this approach. The longer $E$. coli are away from the original host, the more likely it is that differential die-off will skew the type distribution in the water column away from the type distribution in the known-source library (sensu Gordon et al., 2002). To partially address this question, sediment- and waterisolated E. coli OTU distributions were compared. Among the OTU detected more than once in the environmental settings (43 of 156 OTU detected in the environment), 13 were detected in both water and sediment, 23 were detected only in water, and 7 were detected only in sediment. The considerable overlap in sediment and water-detected OTU indicates that largely the same population of E. coli was present in both. The presence of more unique OTUs in water samples than in sediment samples may be because sediment samples were not collected during the first half of the study and because sediment-isolated $E$. coli were biased toward those OTU capable of the most rapid growth in the MPN liquid medium.

\section{Bacteroidales-Based Tool}

Although E. coli concentrations were at or above regulatory limits in 9 of 14 water samples for which Bacteroidales markers were analyzed, neither ruminant nor human sources were detected in most ( 8 of 9) of the contaminated water samples. However, marker $G$ was detected in all water samples. This is compatible with the fact that the general Bacteroides assay (marker $\mathrm{G}$ ) is more sensitive than the host-associated assays (Bernhard and Field, 2000) and with the likelihood that host-associated populations were below marker detection limits. An alternative explanation is that the fecal contamination detected in the stream by analysis for E. coli was from non-human, non-ruminant sources. In bed sediment, Bacteriodales markers identified ruminant (cattle and/or horse) and human as potential sources of fecal contamination. The detections of the general (G), ruminant (R1 and R2) markers, and human marker $(\mathrm{H})$ were distributed throughout the interval 
from 0.0 to $0.3 \mathrm{~m}$. Host-associated Bacteroidales markers were not necessarily detected in the most contaminated sediments (as measured by E. coli concentration). Where the general Bacteroidales marker was not detected, specific Bacteroidales-based markers also would be expected to fail detection attempts. This occurred in all samples except for four sediment samples $(19 \%$ of sediment samples; three of the four were collected on the same date). The importance of not detecting a signal with the general marker where there is detection of the hostassociated marker is unknown.

\section{Integrated Evaluation of Microbial Source-Tracking Tools}

To our knowledge, this is the first report in which library- and marker-based MST results have been integrated in a toolbox approach to detect fecal contamination sources to flowing surface water. Three approaches utilizing coliphage, E. coli, and Bacteroidales-based MST tools were applied to feces, water, and sediment samples to identify bacterial sources in the Plum Creek watershed. Of these, coliphage-based MST was not applicable because coliphage were rarely detected in water samples using the study methods.

The E. coli-based MST tool provided confirmatory evidence that cattle and wildlife were dominant fecal contamination sources within the watershed. The librarydependent $E$. coli analysis used in this study could theoretically have been applied to any population that carries E. coli in its feces; however, each population would have to be represented in the library with ample numbers of $E$. coli isolates for effective use. In comparison, library-independent markers have not yet been developed for all fecal source populations, but the use of existing markers is not constrained by library production (USEPA, 2005). Additionally, classification of a dominant source by E. coli MST was expected to be reliable evidence of contamination in this study on the basis of results for the known source spikes. Negative aspects of the library-dependent E. coli MST were the expense and time required for constructing a reference library, ambiguity in results caused by chronic low levels of false classification, and inability to account for contributions by sources not included in the known source library.

The Bacteroidales-based MST tool had a nearly complete distribution and host specificity for cattle and horses as a class, but the distribution was less reliable for human contamination. Because a limited number of local reference materials are needed to validate the method, rather than a known source library of isolates, the overall cost of validation is less using this tool compared with the E. coli rep-PCR tool. However, the number of identifiable sources is limited by the existence of available markers for each host type. As research continues and markers are developed for more species of interest, this limitation may be overcome. Bacteroidales markers were not detected in samples where E. coli concentrations were one to five times the regulatory limit, although other evidence indicated that cattle were among the dominant contributors of fecal contamination; therefore, utilization of these markers for MST by use of current protocols may be confounded or undermined by high detection limits.

\section{Implications of Sources Identified for Best Management Practice Implementation}

The results in this study provide evidence that cattle and wildlife are major sources of fecal contamination in Plum Creek stream water, whereas cattle, wildlife, and humans contribute to the type of fecal contamination present in bed sediment. Of the fecal sources identified, cattle would be easier to manage to help achieve water quality objectives in the watershed. Implementation of cattle management BMPs likely will have the effect of decreasing E. coli and sediment inputs to the stream. However, the effect of decreasing sediment transport to the stream also can have short-term detrimental effects on stream water quality. After cattle exclusion from streams, bankfull width can decrease because of increased sediment deposition in vegetation on the stream banks (Magilligan and McDowell, 1997). Furthermore, incorporation of riparian buffers might cause an increase in channel slope and erosion of stream bottom sediment in the area of the riparian buffer (Haan et al., 1994) and could cause resuspension of associated bacteria into the stream. Fecal loads from increased wildlife populations using the expanded riparian habitat may counter expected post-BMP water quality improvements expected from incorporation of riparian buffers. Water quality gains also may be tempered because of mortality rates of fecal indicator bacteria associated with finer sediment that is delivered to a stream after passage through a riparian buffer (Anderson et al., 2005). Mortality rates of various fecal indicator bacteria including fecal coliforms, fecal streptococci, and E. coli are less in clay-sized sediments than in coarser sediments (Burton et al., 1987; Sherer et al., 1992; Howell et al., 1996).

The combined effect of multiple cattle management BMPs on improving water quality has not been studied extensively, but the studies that have been completed reported net improvements (Edwards et al., 1997; Brannan et al., 2000; Agouridis et al., 2005). Potential implementation of BMPs by natural resource managers and local farmers to reduce fecal indicator bacteria input from cattle into streams in the Plum Creek watershed will need to consider possible water quality, geomorphological, and interactive effects, as well as economic considerations before they are initiated.

\section{CONCLUSIONS}

Water quality analyses in the Plum Creek watershed in south-central Nebraska showed significant increases in $E$. coli concentrations between Site 1 and Site 2. Targeted sampling and analysis of stream water, stream bed sediment, and reference fecal material in this catchment reach have been used to provide evidence about the origins of $E$. coli contamination in the watershed by use of coliphage, E. coli, and Bacteroidales-based MST tools. This reach was chosen for in-depth investigation be- 
cause it was the most upstream reach in which large concentrations of $E$. coli were detected. Sampling from a portion of the fairly homogeneous (as evidenced by land use, agricultural practices, topography, climate, and water quality) Plum Creek watershed allowed for a small area from which to collect fecal source samples to represent the $E$. coli population from various sources. Similarities of land use characteristics and E. coli concentrations throughout the perennially flowing stream reach indicate that MST results from the targeted samples may be representative of other parts of the Plum Creek watershed as well.

Lack of coliphage detections in Plum Creek precluded its use as a MST tool in this setting. Both the E. colibased and Bacteroidales-based MST tools gave evidence of fecal contamination sources in this watershed. The E. coli-based MST tool (rep-PCR) supported the hypothesis that cattle and wildlife were sources of $E$. coli in both water and sediment, whereas the Bacteroidalesbased MST tool provided evidence that cattle and/or horses contributed fecal contamination in water, and cattle and/or horses and humans contributed fecal contamination to sediment samples. Cattle source contamination in water samples from Site 2 was detected when using E. coli-based MST but very infrequently (1 of 13 samples) when using the Bacteroidales markers. Low detection rates for host-associated markers in the selected catchment reach are an indication that the libraryindependent markers might not always identify sources in waters that are considered contaminated based on fecal indicator bacteria concentrations. At sites with higher contamination levels, the host-associated markers may more reliably detect primary sources of fecal pollution. Although results by E. coli-based and Bacteroidales-based MST methods led to similar interpretations, detection of Bacteroidales markers in sediment more commonly than in water indicates that different tools to track fecal contamination (in this case, tools based on Bacteroidales DNA and E. coli isolates) may have varying relevance to the more specific goal of tracking the sources of $E$. coli in watersheds.

On the basis of the results of this study, the most likely target for management BMPs to reduce $E$. coli loadings in the watershed is cattle. If BMPs are initiated to target cattle source fecal contamination, additional consideration of the stream geomorphology and ability of the stream to recover should be considered before implementing BMPs such as riparian zones or exclusion fencing.

\section{ACKNOWLEDGMENTS}

This research was conducted through formal and informal cooperative agreements between the Nebraska Department of Environmental Quality (NDEQ), the U.S. Geological Survey (USGS), and the U.S. Environmental Protection Agency (USEPA). Support was provided in part by the USEPA through cooperative agreements or grants authorized by Section 104(b)(3) and Section 319 of the Clean Water Act, by the USGS Cooperative Water Program, and by an Augmentation Award from the National Center for Computational Toxicology of the USEPA, Office of Research and Development. The authors are grateful for the cooperation of the landowners in the Plum Creek watershed during this study and for the technical assistance from Cathy Kelty, Jinrang Lu, and Christopher Luedeker. Any opinions expressed in this paper are those of the author(s) and do not necessarily reflect the official positions and policies of the USGS, NDEQ, or USEPA. Any use of trade, firm, or product names is for descriptive purposes only and does not imply endorsement by the U.S. government or the NDEQ.

\section{REFERENCES}

Agouridis, C.T., S.R. Workman, R.C. Warner, and G.D. Jennings. 2005. Livestock grazing management impacts on stream water quality-A review. J. Am. Water Resour. Assoc. 41:591-605.

Anderson, T.W., and D.A. Darling. 1954. A test of goodness-of-fit. J. Am. Stat. Assoc. 49:765-769.

Anderson, K.L., J.E. Whitlock, and V.J. Harwood. 2005. Persistence and differential survival of fecal indicator bacteria in subtropical waters and sediments. Appl. Environ. Microbiol. 71(6):3041-3048.

Bernhard, A.E., and K.G. Field. 2000. A PCR assay to discriminate human and ruminant feces on the basis of host-differences in Bacteroides-Prevotella genes encoding 16S rRNA. Appl. Environ. Microbiol. 66:4571-4574.

Brannan, K.M., S. Mostaghimi, P.W. McClellan, and S. Inamdar. 2000. Animal waste BMP impacts on sediment and nutrient losses in runoff from the Owl Run watershed. Trans. ASAE 43(5):1155-1166.

Burton, G.A., Jr., D. Gunnison, and G.R. Lanza. 1987. Survival of pathogenic bacteria in various freshwater sediments. Appl. Environ. Microbiol. 53(4):633-638.

Calci, K.R., W.I.I.I. Burkhardt, W.D. Watkins, and S.R. Rippey. 1998. Occurrence of male-specific bacteriophage in feral and domestic animal wastes, human feces, and human-associated wastewaters. Appl. Environ. Microbiol. 64:5027-5029.

Cole, D., M.D. Sobsey, and S.C. Long. 2003. Evaluation of F+ RNA and DNA coliphages as source-specific indicators of fecal contamination in surface waters. Appl. Environ. Microbiol. 69:6507-6514.

Dallal, G. 1986. An analytic approximation to the distribution of Lilliefors's Test Statistic for normality. Am. Stat. 40(4):294-296.

Edwards, D.R., T.C. Daniel, H.D. Scott, P.A. Moore, Jr., J.F. Murdoch, and P.F. Vendrell. 1997. Effect of BMP implementation on storm water flow quality of two northwestern Arkansas streams. Trans. ASAE 40(5):1311-1319.

Edwards, T.K., and G.D. Glysson. 1999. Field methods for measurement of fluvial sediment. USGS Techniques of Water-Resources Investigations, Bk 3, Ch. C2, [Online]. USGS, Washington, DC. Available at http://water.usgs.gov/osw/techniques/sedimentpubs. html (verified 20 Dec. 2006).

Francy, D.S., and R.A. Darner. 1998. Factors affecting Escherichia coli concentrations at Lake Erie public bathing beaches. USGS WaterResources Inv. Rep. 98-4241, 41 p. USGS, Washington, DC.

Gordon, D.M., S. Bauer, and J.R. Johnson. 2002. The genetic structure of Escherichia coli populations in primary and secondary habitats. Microbiol. 148:1513-1522.

Griffith, J.F., S.B. Weisberg, and C.D. McGee. 2003. Evaluation of microbial source tracking methods using mixed fecal sources in aqueous test samples. J. Water Health 1(4):141-151.

Guy, H.P. 1969. Laboratory theory and methods for sediment analysis. USGS Tech. of Water-Resources Inv. Bk. 5, Ch. C1. USGS, Washington, DC.

Haan, C.T., B.J. Barfield, and J.C. Hayes. 1994. Design hydrology and sedimentology for small catchments. Academic Press, San Diego.

Hartel, P.G., E.A. Frick, A.L. Funk, J.L. Hill, J.D. Summer, and M.B. Gregory. 2004. Sharing of ribotype patterns of Escherichia coli isolates during base flow and storm flow conditions. USGS Scientific Inv. Rep. 2004-5004. USGS, Washington, DC.

Hitch, D.E., V.C. Walczyk, R.A. Drudik, and J.D. Miller. 2005. Water resources data-Nebraska water year 2005. USGS Water Data Rep. NE-05-1 [Online]. USGS, Washington, DC. Available at http:// pubs.usgs.gov/wdr/2005/ (verified 20 Dec. 2006).

Hitch, D.E., V.C. Walczyk, R.A. Drudik, J.D. Miller, and S.H. Hull. 2004. Water resources data-Nebraska water year 2004. USGS Water-Data Rep. NE-04-1 [Online]. USGS, Washington, DC. Available at http:// pubs.usgs.gov/wdr/2004/wdr-ne-04-1/ (verified 20 Dec. 2006). 
Howell, J.M., M.S. Coyne, and P.L. Cornelius. 1996. Effect of sediment particle size and temperature on fecal bacteria mortality rates and the fecal coliform/fecal streptococci ratio. J. Environ. Qual. 25(6): $1216-1220$.

Hyer, K.E., and D.L. Moyer. 2004. Enhancing fecal coliform total maximum daily load models through bacterial source tracking. J. Am. Water Resour. Assoc. 40(6):1511-1526.

Jenkins, M.B., P.G. Hartel, T.J. Olexa, and J.A. Stuedemann. 2003. Putative temporal variability of Escherichia coli ribotypes from yearling steers. J. Environ. Qual. 32:305-309.

Lamendella, R., J.W. Santo Domingo, D.B. Oerther, J.R. Vogel, and D.M. Stoeckel. 2007. Assessment of fecal pollution sources in a small northern-plains watershed using PCR and phylogenetic analyses of Bacteroidetes 16S rDNA. FEMS Microbiol. Ecol. (in press).

Magilligan, F.J., and P.F. McDowell. 1997. Stream channel adjustments following elimination of cattle grazing. J. Am. Water Resour. Assoc. 33(4):867-878.

Martinez, J., and B. Iglewicz. 1981. A test for departure from normality based on a biweight estimator of scale. Biometrika 68:331-333.

Moore, D.F., D.M. Ferguson, P. Hannah, M. Getrich, V.J. Harwood, M. Brownell, and J. Lukasik. 2005. Evaluation of antibiotic resistance analysis and ribotyping for identification of faecal pollution sources in an urban watershed. J. Appl. Microbiol. 99:618-628.

Moyer, D.L., and K.E. Hyer. 2003. Use of the Hydrological Simulation Program-FORTRAN and bacterial source tracking for development of the fecal coliform total maximum daily load (TMDL) for Christians Creek, Augusta County, Virginia. USGS WaterResources Inv. Rep. 03-4162. USGS, Washington, DC.

National Agricultural Statistics Service. 2004. National Agriculture Statistics Service's 1:100000-scale 2003 cropland data layer, a cropspecific digital data layer for Nebraska, 14 Mar. 2003. USDA, National Agricultural Statistics Service [CD-ROM]. USDA, Washington, DC. Available at http://www.nass.usda.gov/research/Cropland/SARS1a.htm (verified 20 Dec. 2006).

Nebraska Department of Environmental Quality. 2004. 2004 Surface water quality integrated report. Nebraska Dep. of Environmental Quality, Water Quality Division, Lincoln, NE.

Nebraska Department of Natural Resources. 2005. Stream flow daily data-Plum Creek near Smithfield [Online]. Available at http:// dnrdata.dnr.ne.gov/Canal/streamdnr/CanalCal.asp?sta $=6767500 \&$ syear $=1981 \&$ eyear $=2004$ (verified 20 Dec. 2006).

Ott, L.R. 1993. An introduction to statistical methods and data analysis. Duxbury Press, Belmont, CA.

Ritter, K.J., E. Carruthers, C.A. Carson, R.D. Ellender, V.J. Harwood, K. Kingsley, C. Nakatsu, M. Sadowsky, B. Shear, B. West, J.E. Whitlock, B.A. Wiggins, and J.D. Wilbur. 2003. Assessment of statistical methods used in library-based approaches to microbial source tracking. J. Water Health 1:209-223.
Shapiro, S.S., and M.B. Wilk. 1965. An analysis of variance test for normality. Biometrika 52:591-611.

Sherer, B.M., J.R. Miner, J.A. Moore, and J.C. Buckhouse. 1992. Indicator bacterial survival in stream sediments. J. Environ. Qual. 21(4):591-595.

Simpson, J.M., J.W. Santo Domingo, and D.J. Reasoner. 2002. Microbial source tracking: State of the science. Environ. Sci. Technol. 36:5279-5288.

Stoeckel, D.M., M.V. Mathes, K.E. Hyer, C. Hagedorn, H. Kator, J. Lukasik, T. O’Brien, T.W. Fenger, M. Samadpour, K.M. Strickler, and B.A. Wiggins. 2004. Comparison of seven protocols to identify fecal contamination sources using Escherichia coli. Environ. Sci. Technol. 38(22):6109-6117.

USEPA. 2000. Improved enumeration methods for the recreational water quality indicators-Enterococci and Escherichia coli. Office of Science and Technology, Washington, DC.

USEPA. 2001. Method 1602-Male-specific $(\mathrm{F}+)$ and somatic coliphage in water by single agar layer (SAL) procedure. EPA 821-R01-029. USEPA, Washington, DC.

USEPA. 2004. Quality assurance/quality control guidance for laboratories performing PCR analyses on environmental samples, EPA 815-B-04-001. USEPA, Washington, DC

USEPA. 2005. Microbial source tracking guide document. EPA/600-R05-064. USEPA, Cincinnati, OH.

USGS. 2004. National field manual for the collection of water-quality data. Tech. of Water-Resources Inv., Bk. 9, Ch. A1-A9 [Online] USGS, Washington, DC. Available at http://pubs.water.usgs.gov/ twri9A (verified 20 Dec. 2006).

Wahl, F.E. 1981. Soil survey of Gosper County, Nebraska. USDA Soil Conservation Service, Washington, DC.

Wiggins, B.A. 1996. Discriminant analysis of antibiotic resistance patterns in fecal streptococci, a method to differentiate human and animal sources of fecal pollution in natural waters. Appl. Environ. Microbiol. 62:3997-4002.

Wiggins, B.A., P.W. Cash, W.S. Creamer, S.E. Dart, P.P. Garcia, T.M Gerecke, J. Han, B.L. Henry, K.B. Hoover, E.L. Johnson, K.C. Jones, J.G. McCarthy, J.A. McDonough, S.A. Mercer, M.J. Noto, H. Park, M.S. Phillips, S.M. Purner, B.M. Smith, E.N. Stevens, and A.K. Varner. 2003. Use of antibiotic resistance analysis for representativeness testing of multiwatershed libraries. Appl. Environ. Microbiol. 69:3399-3405.

Wilhelm, L.J., and T.L. Maluk. 1998, Fecal indicator bacteria in surface waters of the Santee River Basin and coastal drainages, North and South Carolina, 1995-98. U.S. Geol. Surv. Fact Sheet FS-085-98.

Zhang, H.X., M. Harrington, J.T. Mauro, L.A. Fillmore, and J. Wheeler. 2002. Identity known-Using bacterial source tracking in fecal coliform TMDL development and implementation. Water Environ. Technol. 14(4):20-24. 


\section{VALIDATION STEPS FOR LIBRARY-DEPENDENT SOURCE-TRACKING RESULTS AND INTERPRETATIONS}

Method-validation studies on library-dependent methods for microbial source tracking (MST) suggest that these approaches are prone to error, particularly when they rely on small libraries (Griffith et al., 2003; Stoeckel et al., 2004; Moore et al., 2005). The library used in the associated manuscript contained 409 isolates. Although this number of isolates is small relative to current recommendations (Jenkins et al., 2003; Wiggins et al., 2003), these isolates were obtained from individuals representing between 7 and $75 \%$ of total populations of those sources in the target subwatershed. If what is important for accurate library-dependent MST is representation of the source populations, rather than the absolute size of the libraries, then the 409-isolate library should be sufficient for the task in this setting. Libraryindependent methods for microbial source tracking, such as coliphage typing and detection of host-associated molecular markers, also must be validated in the time and space of the individual study (USEPA, 2005). Validation information for the library-independent methods was presented in the associated text. This section provides supplemental material related to the extensive validation testing of library-dependent (E. coli-based) sourcetracking results and interpretations.

The known-source library contained rep-PCR patterns for 201 cattle-isolated E. coli, 29 horse-isolated E. coli, 69 human-isolated E. coli, and 110 wildlife-isolated E. coli. In all, 220 operational taxonomic units (OTU) were assigned among the 409 known source isolates207 specific to one host and 13 cosmopolitan (isolated from more than one host), as described in the associated report. The following quality control data were used in the various validation steps described in this section:

Twenty duplicate pair analyses of known-source E. coli; Fifteen duplicate pair analyses of water- or sedimentisolated E. coli;

Thirty-six replicate analyses of the positive-control E. coli from the American Type Culture Collection (ATCC), identified as strain 25922;

Five single-blind, single-source-spiked challenge samples.

\section{Quality Control Characteristics of Analytical Data}

The precision of the rep-PCR analytical method was characterized by the 20 replicate analyses and the 36 positive control repeated measures analyses. The 36 positive control analyses were further used to validate PCR product patterns produced in each run, and negative control (blank) samples were used to test for PCR products that might come from contamination.

\section{Blanks and Positive Controls}

None of 17 PCR blank reactions showed evidence of DNA amplification when analyzed on the Bioanalyzer or by agarose gel electrophoresis. The repeated-measure positive control (ATCC 25922) run with each batch of PCR showed the expected PCR product patterns in all runs.

\section{Replicate Isolates}

Two of 35 sample replicates (6\%) showed visible differences sufficient to be assigned to a different OTUone replicate showed a substantial difference in the normalization (very similar pattern, pattern offset more than typical in other replicates); the other replicate had several differences in the pattern(s) of PCR products (some caused by a major difference in intensity). Among the 36 repeated measures on strain ATCC 25922, four (11\%) showed a difference in the pattern(s) of PCR products because of a major difference in intensity. There was no evidence that isolates were mixed up, that banding patterns shifted during the timeframe of these analytical runs, or that more than 6 to $11 \%$ of isolates were wrongly assigned to different subtypes.

The 35 replicate analyses had average similarity (Pearson coefficient, 5\% optimization to account for normalization bias) of $88 \%$ (interquartile range 82 to $96 \%$ ), and the replicate samples often did not cluster together on the dendogram - this underscores the need for professional judgment when assigning OTU. Average similarity among the repeated-measures isolate (ATCC 25922 ) was $84 \%$ (interquartile range 76 to $93 \%$ ).

\section{Replicate Samples}

Replicate analyses were done on four feces samples to evaluate whether (i) the sampling effort was sufficient to represent the diversity of major $E$. coli types in various samples and (ii) the same types would be recovered from independent analyses of different subsamples from the same fecal sample (data not shown). A replicate analysis also was done on one test water sample to evaluate whether the same results could be obtained on independent samples at the same site and time.

The same OTU frequently were isolated in replicate analyses of fecal samples, which indicated that the sampling effort invested in human and cattle fecal material was sufficient to represent the E. coli OTU diversity present in the individual feces sample. In all four cases, the major OTU was recovered in duplicate analysis of fecal suspension. In three of four cases, the major OTU also was recovered in a different fecal suspension prepared from a different location in the fecal mass. Diversity in water, on the other hand, was much higher and the sampling effort for the individual water sample did not completely represent the total diversity present in the sample. This diversity was expected from a prior study on a much larger river system, the Chattahoochee, in Georgia, in which the same ribotypes (analogous to OTU) rarely were recovered from various samples even with extensive sampling effort (Hartel et al., 2004).

\section{Classification of $E$. coli to Source}

Various strategies can be used to classify E. coli as to source by comparison to a known source library of data 
patterns (Ritter et al., 2003). The most commonly used strategies include direct matching of OTU in the library to OTU of unknowns, nearest neighbor (or maximum similarity) classification, and classification by discriminant analysis. These three strategies were evaluated for effectiveness against the experimental data set.

\section{Classification by 1:1 Operational Taxonomic Unit Matching}

Each isolate was assigned an OTU. Briefly, the fifthpercentile similarity among repeated measures data was used as a primary criterion to describe variability in the method. Isolates that were more similar than the repeated measures criterion were considered indistinguishable members of the same OTU. Operational taxonomic units defined in this way were checked and modified as needed by best professional judgment because, in many cases, the human eye could detect similarities and differences that the BioNumerics software (Applied Maths, Sint-Martens-Latem, Belgium) did not recognize. In cases where a sediment- or water-isolated E. coli was assigned to an OTU that was otherwise exclusively found in one source category, that isolate was classified to the matched source.

Accuracy by use of similar OTU-matching strategies has been reported to be higher than other analytical approaches to classification in methods-comparison studies (Ritter et al., 2003; Stoeckel et al., 2004). However, the 1:1 matching strategy often results in an uncomfortably large proportion of isolates for which classification is unknown (Ritter et al., 2003; Stoeckel et al., 2004). Interpretation of results in terms of major fecal contamination sources to water is muddied when a large proportion of water-isolated $E$. coli remains unclassified. In this data set, 117 of 154 water-isolated E. coli and 55 of 66 sediment-isolated $E$. coli could not be classified by the 1:1 OTU matching approach. Isolates could not be classified if there was no OTU match in the known source library or if the OTU matched isolates were coming from more than one source (cosmopolitan OTU).

\section{Classification by Script-Based Nearest Neighbor Matching}

The nearest neighbor (NN) approach to classification assigns an isolate of unknown origin to the source of the known source isolate to which it is most similar. This approach can lead to classification error if the test isolate is dissimilar to all known source library isolates or is equally similar to known source isolates from different sources. A custom script in the BioNumerics software called "Bootstrap" can be used for improved NN classification. The Bootstrap script resamples the library and assigns isolates of unknown origin to a source in each resampling. The results table includes the source to which each isolate was assigned most frequently, the maximum similarity to a known source isolate $(\mathrm{S})$, and the proportion of iterations in which the isolate of unknown origin was assigned to the source $(\mathrm{P})$. The strategy for acceptance of a classification based on $\mathrm{S}$ and $\mathrm{P}$ is user-defined.
In this study, the 20 duplicate pair analyses from known sources were used to help generate an acceptance strategy. One member of the pair was included in the known source library, and the other was treated as an unknown. Bootstrap sample sizes of 15,30 , and 50 were tested, and results were scored true or false for each test. By use of a sample size of 30 isolates, 17 of the 20 duplicates were classified correctly. Values for $\mathrm{S}$ and $\mathrm{P}$ among the correct and incorrect classifications were evaluated to establish acceptance criteria. Low stringency acceptance criteria were $\mathrm{S}>85 \%$ and $P>40 \%$; by use of these criteria, 1 of 3 incorrect classifications would be accepted, and 13 of 17 correct classifications would be accepted. Higher stringency acceptance criteria were $\mathrm{S}>90 \%$ and $P>60 \%$; by use of these criteria, 0 of 3 incorrect classifications would be accepted, but only 8 of 17 correct classifications would be accepted. Results of NN classification with the lower stringency acceptance criteria are presented in the associated text.

\section{Classification by Discriminant Analysis}

In general, 1:1 OTU matching and NN matching result in failure to classify a large number of isolates. Centroid-based classification strategies, such as discriminant analysis, are sometimes used to classify more isolates on the basis of within-source commonalities (Wiggins, 1996). For these strategies to work, however, there must be some degree of structure to the data set such that isolates from the various sources can be discriminated. One way to evaluate whether centroidbased strategies are likely to work is to plot the data in two or three dimensions by a technique such as multidimensional scaling. Figure S1 depicts the known-source isolates, which in this data set do not naturally segregate by their rep-PCR characteristics; therefore, centroidbased methods of analysis were considered inappropriate for this data set.

\section{Evaluation of Accuracy}

\section{Known Source Single Blind Challenge Samples}

Known source spikes were created to evaluate classification error by each analytical approach (Table S1). The spikes were submitted blind to the analyzing laboratory and contained fecal material from a single known source, generally from at least 20 individuals, except for the horse spike (because there were only eight horses in the watershed) and the chicken spike, which consisted of a fresh fecal sample from only one animal. False positive classifications at low levels were routine; in two cases the overall sample classification (dominated by cattle or human feces) would have been correct; in two cases, the sample could not be clearly classified; in the fifth case, the wrong classification would have been given (classified as cattle when, in fact, the contamination source was chicken, not in the known source library, and the sample should have been deemed unclassifiable). Except in the unlikely case where a dominant source was not in the library, classification of a dominant source 


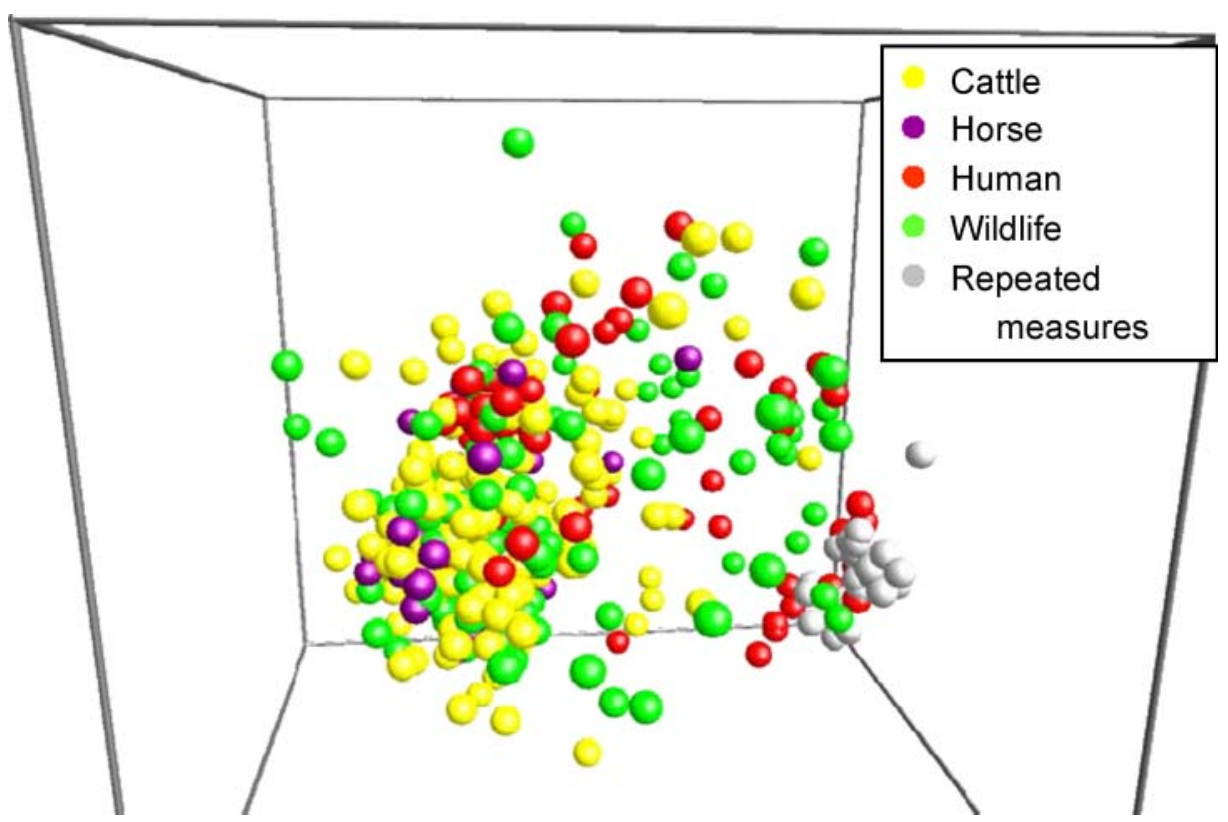

Fig. S1. Multi-dimensional scaling plot of isolates in the known source library. For effective discrimination by centroid-based statistical methods, the isolates should cluster by source.

was expected to be useful as confirmatory evidence of source in this study on the basis of results for the known source spikes.

\section{Validation Summary}

The assumptions behind library-dependent MST tools (in this case, E. coli libraries) generally were supported in this data set (see USEPA, 2005, for full details of assumptions). First, the method must be able to reproducibly discriminate various types; in this study, duplicate analyses allowed measurement of precision (numeric value variable depending on similarity metric used), and 220 types were detected within the limits of method precision with less than $10 \%$ error. Second, the types detected must be specific to host; in this study, only 13 of the 220 types $(6 \%)$ were detected in multiple hosts (cosmopolitan). Third, the method must be able to detect the source in spiked samples; in this study, the correct source was detected in two of three attempts, and the incorrect classification was for a ringer (a source not in the known source library) for which the spike was created from a single individual's feces. In the remaining two samples, classification of a source was not attempted be- cause multiple sources were indicated. In one of these cases (wildlife), the pattern of cosmopolitan isolates indicated that wildlife likely used animal feces as a food source, making discrimination of wildlife samples from other sample types difficult. In the other case (horses), the source population was very small so classification was made more difficult because the library was disproportionate for that source. On the basis of results of these validation steps, the E. coli-based MST tool as applied in this setting provided reproducible assignment to types and the types defined tended to be unique to source; however, the value of classifications was limited by the following exceptions: (i) the tool was unable to detect when a source was not represented in the library, so if the sanitary survey assumptions of likely sources failed then the analysis may also fail; (ii) the tool falsely classified many isolates from one source (wildlife; raccoons and opossums) that may have used feces of other hosts as a food source; and (iii) the tool was unable to detect feces from one source that had disproportionately low representation in the library (horses; only 7\% of library isolates, whereas ideal target representation in a four-source library would be $25 \%$; fewer isolates were included because there were very few horses in the study area).

Table S1. Microbial source-tracking results of single blind known source spike samples. OTU, operational taxonomic unit; NN, nearest neighbor; Cosmopolitan, OTU detected in more than one source; Number in parentheses is the number of isolates from that sample that matched to a particular source.

\begin{tabular}{|c|c|c|c|c|}
\hline Feces source & OTU 1:1 direct matching & BioNumerics NN (lower stringency) & BioNumerics NN (higher stringency) & Expected dominant source $\dagger$ \\
\hline Horse & horse (1); unknown (9) & cattle (3); horse (5); unknown (2) & cattle (1); horse (2); unknown (7) & unclassified \\
\hline Chicken & cattle (1); unknown (9) & cattle (6); wildlife (1); unknown (3) & cattle (4); wildlife (1); unknown (5) & cattle \\
\hline Human & $\begin{array}{l}\text { human (4); unknown (3); } \\
\text { cosmopolitan (3) }\end{array}$ & $\begin{array}{l}\text { cattle (1); human (6); wildlife (1); } \\
\text { unknown (2) }\end{array}$ & $\begin{array}{l}\text { cattle (1); human (5); wildlife (1); } \\
\text { unknown (3) }\end{array}$ & human \\
\hline Cattle & cattle (7); unknown (3) & cattle (6); horse (1); unknown (3) & cattle (3); horse (1); unknown (6) & cattle \\
\hline Wildlife & $\begin{array}{l}\text { horse (2); human (1); wildlife } \\
\text { (1); cosmopolitan (4); } \\
\text { unknown (1) }\end{array}$ & $\begin{array}{l}\text { cattle (2); horse (1); human (3); } \\
\quad \text { wildlife (2); unknown (1) }\end{array}$ & $\begin{array}{l}\text { horse (1); human (3); wildlife (2); } \\
\text { unknown (3) }\end{array}$ & unclassified \\
\hline
\end{tabular}

$\dagger$ No objective criteria are available by which to evaluate the expected dominant source; therefore, our criteria were arbitrary based on the available data set. When (1) one source comprised more than half of the classified isolates, (2) the other classifications were distributed among multiple sources, and (3) the three tests were in agreement, then the source was identified as the expected dominant source of contamination to the sample. 